\title{
Opportunities and barriers to pre-assembled and/or pre-casted systems in retrofitting actions
}

\author{
A. Boeri, J. Gaspari \& F. Dallacasa \\ Department of Architecture, University of Bologna, Italy.
}

\begin{abstract}
The introduction of severe requirements concerning energy efficiency, combined with the need to boost retrofitting actions while reducing time, impacts and costs, offer new fields of action for pre-assembled and dry construction systems in the building sector, especially in the refurbishment of the residential stock. This paper describes the initial results of a study run by a research team of the University of Bologna, Department of Architecture, concerning this topic. The study was carried out in two stages: the first investigated the barriers affecting the application of preassembled and/or pre-casted systems to retrofitting, such as law, technical and geometrical constraints; the second investigated the most effective solutions to be pursued. The following factors were key drivers for the refurbishment techniques: lightweight of components and systems suitable when a small residual loading capacity is still available; open implementation process, aimed to allow further upgrade in a future stage; controlled and monitored construction process; strong reduction in construction time as well as in the environmental impacts of the building site. The paper describes how pre-assembled systems could be adapted to the constraints of existing buildings, while offering the benefits and advantages of an effective management during both the design and construction phase.
\end{abstract}

Keywords: energy retrofitting, pre-assembled systems, potential barriers.

\section{Introduction}

According to Directives 2010/31/EU and 2012/27/EU a great part of the efforts aimed at improving energy efficiency in the building sector will be addressed to renovate the existing building stock in the next years. A number of studies $[1,2]$, shows that the largest part (46\%) of this stock - and especially the residential one 
- was built between the end of the Second World War and the 70s to meet the post-war demand. This means that almost half of the total housing stock is more than thirty years old and starts to show the effects of its physiological obsolescence. If the stock built during the $80 \mathrm{~s}$ and the $90 \mathrm{~s}$ is also considered, the share increases to more than $80 \%$ meaning that four fifths of the housing stock is totally or partially inadequate in meeting the current standards in terms of thermal behaviour, energy efficiency, quality and comfort. In order to fulfil the increasing level of expected performance as well as the introduction of new requirements, the building envelope became the field of intensive research concerning strategies, technological solutions, materials and products to be adopted for retrofitting existing buildings. This led to increase the complexity and the interaction between the layers defining the building envelope section with the consequence that a more accurate design and construction process is required to ensure effective results. If this seems to be an unavoidable condition for new construction, it is far to be assumed as the typical one in renovation processes where many differences occur according to specific constraints.
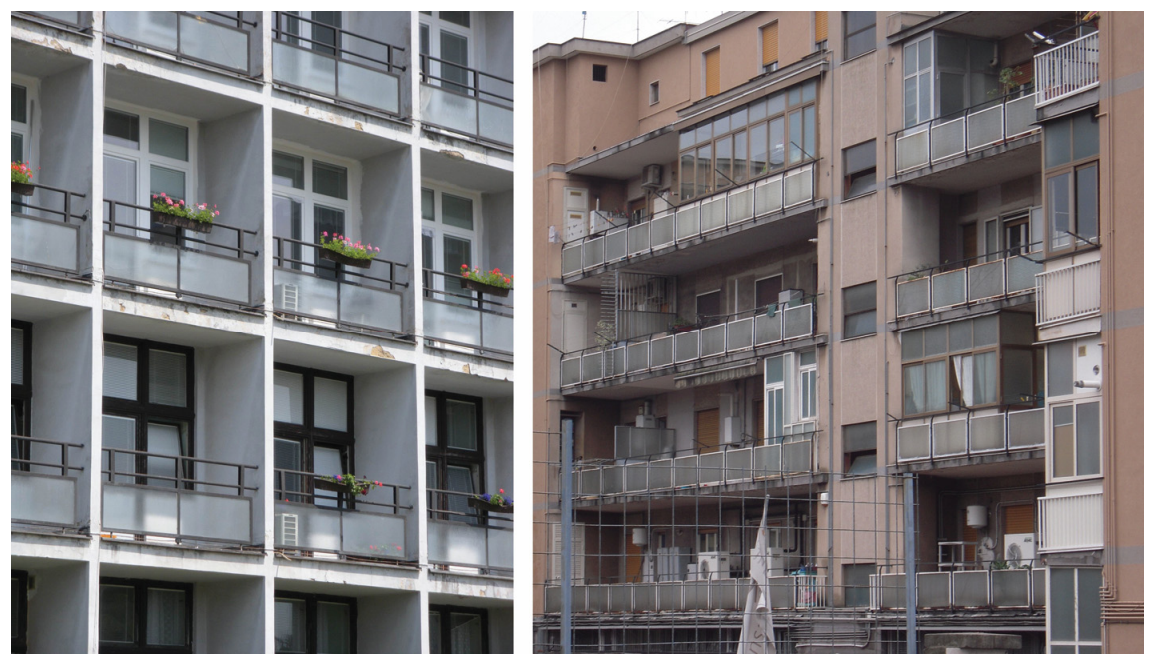

Figure 1: Examples of the building stock under investigation.

In order to reduce construction failures, to increase the reliability of the solution adopted and to speed up the construction process (reducing time, impacts and waste) pre-assembled and dry construction systems are widely investigated as a viable strategy to boost the renovation of the existing building stock, especially the residential one. This paper offers a synthesis of a wider research activity focused on the opportunities related to application of pre-assembled systems in the field of renovation considering limits and barriers as well as the potential benefits concerning design and construction phases [3]. Within the above-mentioned research project, the specific goal of this study is to design a set of viable solutions according to different starting conditions involving the existing buildings and to 
assess their thermo-hygrometric performances in relation to different climatic conditions. The main goal is to define a methodology of intervention on existing buildings using and adapting pre-assembled solutions in order to optimize the relation between weight-volume-performance.

\section{Limits and barriers related to retrofitting actions}

The effectiveness of the strategies to be adopted for retrofitting is strictly connected with a number of intrinsic and extrinsic factors which can limit the field of action. Therefore a preliminary analysis of limits and barriers is required to point out the most suitable and adaptable solutions able to overcome the existing constraints and to meet the expected energy saving targets.

Energy behaviour of existing buildings depends on a number of factors such as features and characteristics related to the original technological solutions and construction systems as well as on typology and efficiency of equipment. All the decisions involving these factors could heavily influence the final overall energy performance [4]. Despite each intervention has its own specificity, this paper based on a number of case studies analysis - focuses on the common key elements to be included in a methodological design approach able to overcome recurring barriers affecting renovation processes. This study adopts a cross-disciplinary approach aimed at collecting a number of different experiences, drafting a clear picture of the most frequent barriers (such as insufficient or non-restricting regulations, lack of incentives or subsided funds, implications related to final users behaviour, etc.) occurring in the European contexts [5-7] and making available an inventory of effective solutions and best practices. Constraints and limitations are analysed according to two main families: intrinsic and extrinsic barriers.

\subsection{Intrinsic barriers}

This group includes a number of barriers mainly referred to the original layout and construction system of the existing building such as the general morphology and geometry of the spaces, the structural scheme and materials adopted as well as the quality of products and of construction process itself: all these factors can heavily influence the renovation strategy. The residual loading capacity of the building often require the adoption of lightweight solutions, therefore the choice of dry assembled options is widely considered a viable solution. In addition to this, the preassembled system is required to be adaptable to variable geometrical constraints and to tune the intensity of intervention according to the starting conditions. If the preassembled system replaces completely the existing façade it will be required to fit with the arrangement of the structural elements, while if it implements the existing façade it could be influenced by the original openings.

\subsection{Extrinsic barriers}

Despite the great efforts spent in developing effective technological solutions, a number of implications dealing with energy issues, climate changes, and economic development are still underestimated. It has been observed that the most critical 
factors that can reduce the current number of efficient renovation initiatives are non-technical barriers related to legal, financial, social constraints strongly limiting the feasibility of interventions much more than the technical obstacles.

A synthesis of the principal barriers detected according to the investigated case studies and based on a literature review in this field is provided in table 1.

Table 1: Intrinsic and extrinsic barriers.

\begin{tabular}{|c|c|c|}
\hline \multirow{3}{*}{ 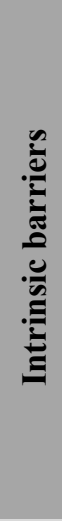 } & Geometrical & $\begin{array}{ll}\text { - } & \text { Structural layout } \\
\text { - } & \text { Façade module } \\
\text { - } & \text { Openings } \\
\text { - } & \text { Floor height } \\
\text { - } & \text { Alignments } \\
\end{array}$ \\
\hline & $\begin{array}{l}\text { Original construction } \\
\text { system }\end{array}$ & $\begin{array}{l}\text { - } \text { Materials } \\
\text { - } \text { Integrability } \\
\text { - } \text { Adaptability } \\
\text { - } \text { Chance to disassemble } \\
\end{array}$ \\
\hline & $\begin{array}{l}\text { Logistic and } \\
\text { construction process }\end{array}$ & $\begin{array}{l}\text { - Organization of the building site } \\
\text { - Transport and connections } \\
\text { - Surroundings } \\
\text { - Distance from other buildings }\end{array}$ \\
\hline \multirow[b]{3}{*}{ 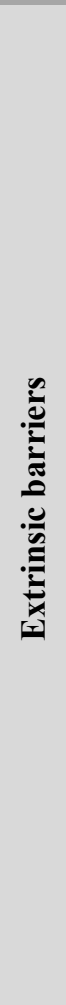 } & Legal & $\begin{array}{l}\text { - } \text { Contractual } \\
\text { - } \text { Guarantee period } \\
\text { - } \text { Local building plants } \\
\text { - } \text { Directive on energy performance }\end{array}$ \\
\hline & Financial & $\begin{array}{l}\text { - } \text { Life-cycle cost } \\
\text { - } \text { Payvestment cost time } \\
\text { - } \\
\text { Enpact on tax assessments } \\
\text { Enice }\end{array}$ \\
\hline & $\begin{array}{l}\text { Organization of the } \\
\text { sector (building } \\
\text { sector, market) }\end{array}$ & $\begin{array}{l}\text { - Organization of the sector } \\
\text { - } \text { Dialogue understanding between partners } \\
\text { - } \text { Custability of technological solutions } \\
\text { - } \text { Aesthetics } \\
\text { - } \text { Cultural values } \\
\text { - Publial planning } \\
\text { - } \text { provider individual energy supply } \\
\text { - } \text { energy performance } \\
\text { - } \text { User behavior/comfort } \\
\text { - } \text { Sultural aspects } \\
\text { - Age/generational aspects } \\
\end{array}$ \\
\hline
\end{tabular}




\section{Pre-assembled system design criteria}

Once limits and barriers have been identified, the research focused on studying how to overcome these constraints in order to adapt a set of preassembled solutions - usually developed and used in new construction - to renovation and how to maximize the effectiveness of interventions in terms of energy savings, cost feasibility and reduction of impacts. Design criteria are developed according to an energy concept involving the morphological, functional and technological features to optimize the thermal and energy behaviour with reference to different contexts and climatic conditions [8].

\subsection{Advantages and opportunities of pre-assembled solutions}

The idea of studying a set of pre-assembled solution to be used for renovating the existing building stock is strictly connected with the aim to reduce construction time and impacts while increasing the performance and the reliability of the system itself. This is due to a completely different construction approach compared to onsite processes: the system is designed to be produced and assembled off-site according to procedures and testing methods which ensure the performance level is closed to the expectations [9]. Each element and layer composing the system is adequately tested and combined according to a specific functional and technical

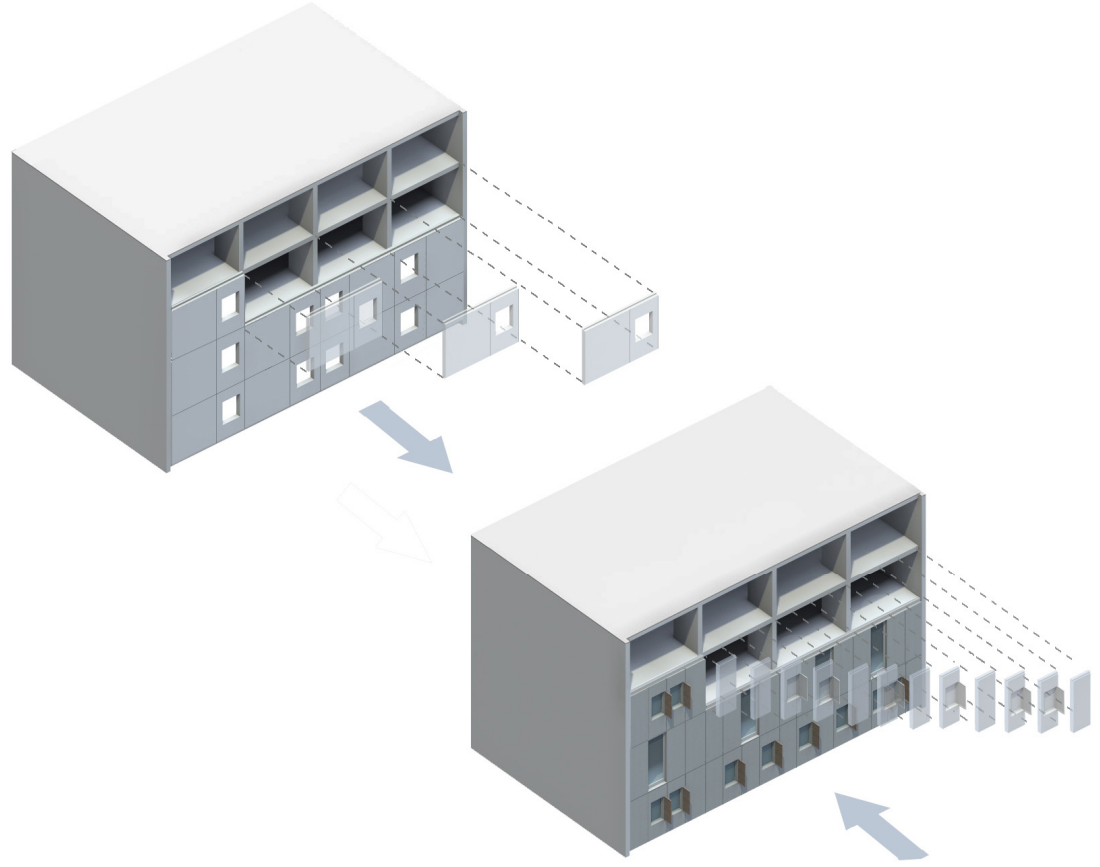

Figure 2: Construction process phases. 
sequence which provides a multilayered pre-assembled panel. As a consequence, construction failure due to human errors are strongly reduced. However this requires increasing resources and efforts during the design stage in order to provide adequate answers to all the potential critical factors. Details of horizontal and vertical sections of the pre-assembled module have to be provided in order to define and/or customize the size and the connections. A set of connections with a number of possible existing structures was investigated in order to assess the feasibility according to different starting conditions.

The system is based on a modular sandwich panel - from floor-to-floor - whose size is customized according to the general geometry of the façade modules. Each panel usually varies between 1.2 and 1.5 meters wide in order to move it easily with a mobile crane and to speed up the assemblage.

A steel frame will ensure an adequate supporting structure for the internal and external panels as well as for hosting insulation. Each panel is layered according to specific thermo-hygrometric requirements related to site conditions. Therefore, specific analysis concerning thermal, acoustic and seismic features have to be performed. The panels will also favourite corrective measures for thermal bridges as well as the integration of equipment for heating and cooling.

One of the most important benefits of this approach is the lightweight of the panels, which allow adopting this solution even though the existing building provides a reduced load bearing capacity.

\subsection{Adaptability of design solutions to different scenarios}

As each renovation action has to face different starting conditions concerning the geometrical and structural layout [10] as well as the construction system originally adopted, two main possible scenarios were identified:

Scenario 01 - the existing façade can be completely replaced - this is the case, for example, of a precast concrete panels' façade - with new preassembled elements which are supported by the existing bearing structure.

Scenario 02 - the existing façade can't be removed - this is the case, for example, of a brick block façade - and it is implemented by the new preassembled elements which are layered on the existing ones.

According to the state of art and to the analysed case studies, a number of variations based on the typical façade module were studied and evaluated in order to define the most effective construction and assemblage procedure.

The preassembled module developed for scenario 01 is based on floor-to-floor panels whose width can range between 1.2 and 1.5 meters supported by a steel frame which is connected with the existing structure using metal joints (designed according to the geometrical constraints of the original structure). Each panel is layered - as figure 3(a) shows - in order to provide a finished, efficient element on both sides.

The finishing of the internal surface requires a plasterboard strip to cover the joints between each panel, the application of a surface filler and the final painting of the surface. The external surface is finished using photo-catalytic cement panels; other claddings, such as metal sheets or timber boards, can be considered optionally. 


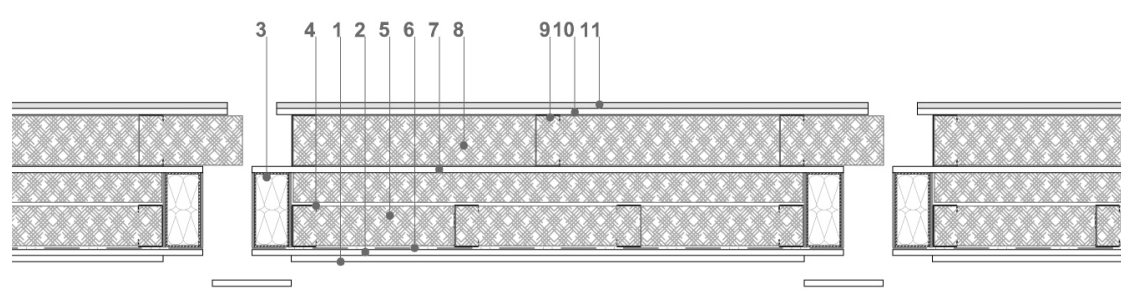

(a)

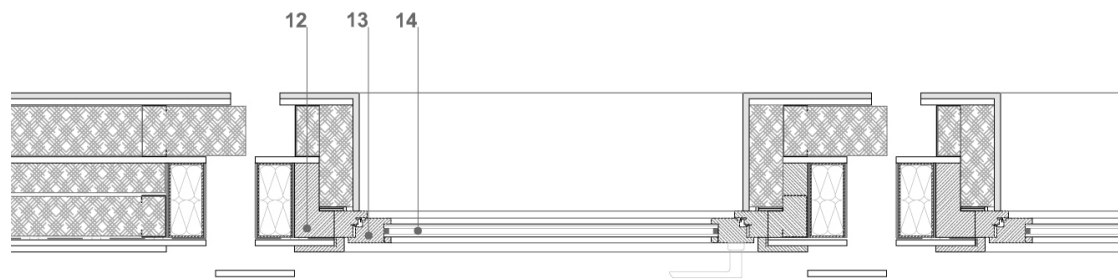

(b)

\begin{tabular}{rll}
\hline 1 & Plasterboard [type 01] (to be completed on site) & $\mathrm{mm} \mathrm{12,5}$ \\
2 & Plasterboard [type 02] & $\mathrm{mm} \mathrm{12,5}$ \\
3 & Pre-insulated bearing steel frame & $\mathrm{mm}$ 60x120 \\
4 & Metal substructure & $\mathrm{mm} \mathrm{50x75}$ \\
5 & Fiberwood insulation & $\mathrm{mm} \mathrm{80+40}$ \\
6 & Vapour barrier & $\mathrm{mm} \mathrm{12,5}$ \\
7 & Plasterboard [type 02] & $\mathrm{mm} \mathrm{100}$ \\
8 & Fiber wood insulation & $\mathrm{mm} \mathrm{50x100}$ \\
9 & Metal substructure & $\mathrm{mm} \mathrm{12,5}$ \\
10 & Plasterboard [type 03] (waterproofed) & $\mathrm{mm} \mathrm{15}$ \\
11 & photo-catalytic cement panel & \\
12 & supporting element of the window & \\
13 & window & \\
14 & glazing & \\
\hline
\end{tabular}

Figure 3: Typical sections of preassembled panels for scenario 01.

Three fiberwood layers provide insulation, separated by an additional plasterboard layer, which protects the steel frame. A number of variations can be arranged to provide glazed modules as shown in figure $3(\mathrm{~b})$.

The preassembled module developed for scenario 02 is based on floor-to-floor panels whose width can be adapted to the morphology of the original façade (generally in a range between 0.6 and 1.2 meters), supported by vertically profiled steel elements to be hung to joints placed on the existing building envelope (see figure 4). 


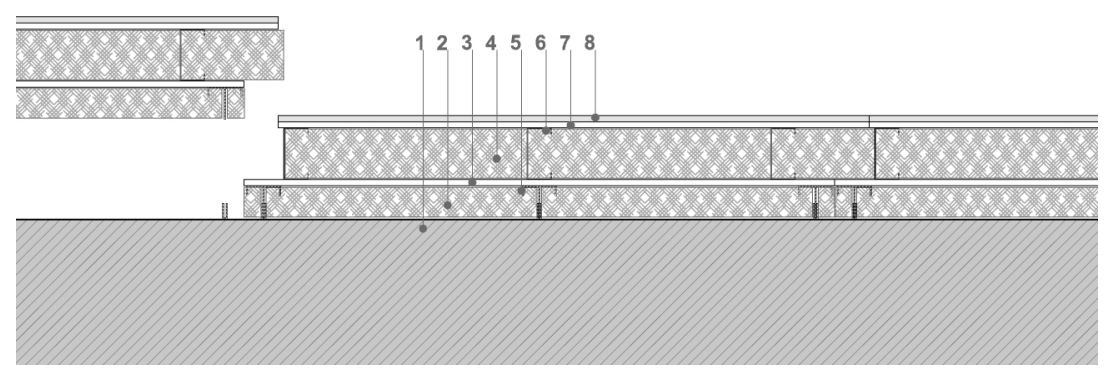

\begin{tabular}{lll}
\hline 1 & Existing structure & \\
2 & Fiber wood insulation & $\mathrm{mm} \mathrm{60}$ \\
3 & Plasterboard [Type 02] & $\mathrm{mm} \mathrm{12,5}$ \\
4 & Fiber wood insulation & $\mathrm{mm} \mathrm{100}$ \\
5 & Bearing steel elements & $\mathrm{mm} \mathrm{75(h)}$ \\
6 & Metal substructure & $\mathrm{mm} \mathrm{50x100}$ \\
7 & Plasterboard (waterproofed) & $\mathrm{mm} \mathrm{12,5}$ \\
8 & photo-catalytic cement panel & $\mathrm{mm} \mathrm{15}$ \\
\hline
\end{tabular}

Figure 4: Typical section of preassembled panels for scenario 02.

The advantage of this option compared to a conventional insulation layer is that panels are provided of battens which simplify the assemblage and ensure an efficient functional and thermal result.

Preassembled solutions not require the use of scaffolding, thus speeding up the construction process and reducing time and costs as well as the impacts on the building site.

\subsection{Hygro-thermal performances}

The developed preassembled options are aimed at ensuring an efficient correction of thermal bridges and improving the general thermal performance of the building envelope, therefore the typical section of the panels can vary according to climate and specific boundary conditions of the location [11]. That means the general geometry and layered arrangement of the panel will be the same but thickness and typology of insulation as well as of finishing or cladding could be chosen after a thermal and energy evaluation is performed. However a preliminary energy and thermal assessment of the typical sections allowed to point out a limited number of options able to satisfy most of the recurring climate conditions of the Italian market (which reflects two main scenarios: Continental and Mediterranean climate) [12]. Evaluation was performed using the software Termolog EpiX 3 according to the parameters foreseen by national rules (as the collected case studies were placed in different regions of Italy). At national level, recurring and critical conditions consist in rigid temperatures during the winter and overheating during summer; therefore a specific technological solution was tested to provide an efficient answer in both of these different seasons. 
In order to increase the performance of the building envelope, insulation of the preassembled module (referred to scenario 01) was divided into three different layers varying thickness and density and choosing products able to increase the mass of the panel [13]. Simulation and assessment were performed using fiberwood insulation layers which allow to reach a thermal lag of 15 hours and a temperature damping of $8,92 \%$. Table 2 provides a synthesis of the principal features of the layers used in preassembled designed for scenario 01 .

Table 2: Features of preassembled designed for scenario 01 tested in the typical Mediterranean climate.

\begin{tabular}{|c|c|c|c|c|c|c|}
\hline & Layer & Thickness & $\begin{array}{c}\text { Thermal } \\
\text { conductivity }\end{array}$ & $\begin{array}{l}\text { Thermal } \\
\text { resistance }\end{array}$ & $\begin{array}{c}\text { Specific } \\
\text { heat }\end{array}$ & Density \\
\hline & unit & $\mathrm{m}$ & $\lambda\left[\mathrm{W} / \mathrm{m}^{2} \mathrm{~K}\right]$ & $\mathrm{R}\left[\mathrm{m}^{2} \mathrm{~K} / \mathrm{W}\right]$ & $\begin{array}{c}\mathrm{Cp} \\
{[\mathrm{kgJ} / \mathrm{kgK}]}\end{array}$ & $\begin{array}{c}\rho \\
{\left[\mathrm{kg} / \mathrm{m}^{3}\right]}\end{array}$ \\
\hline 1 & $\begin{array}{l}\text { Internal surface } \\
\text { resistance }\end{array}$ & & & 0.13 & & \\
\hline 2 & $\begin{array}{l}\text { Plasterboard } \\
\text { [type 01] }\end{array}$ & 0.0125 & 0.21 & & 1.3 & 900 \\
\hline 3 & $\begin{array}{l}\text { Plasterboard } \\
\text { [type } 02]\end{array}$ & 0.0125 & 0.39 & & 1.0 & 1200 \\
\hline 4 & Vapour barrier & 0.0040 & 0.6 & & 1.0 & 0.1 \\
\hline 5 & $\begin{array}{l}\text { Fiber wood } \\
\text { insulation }\end{array}$ & 0.0800 & 0.036 & & 2.1 & 50 \\
\hline 6 & $\begin{array}{l}\text { Fiber wood } \\
\text { insulation }\end{array}$ & 0.0400 & 0.042 & & 2.1 & 120 \\
\hline 7 & $\begin{array}{l}\text { Plasterboard } \\
\text { [type } 02]\end{array}$ & 0.0125 & 0.39 & & 1.0 & 1200 \\
\hline 8 & $\begin{array}{l}\text { Fiber wood } \\
\text { insulation }\end{array}$ & 0.1000 & 0.042 & & 2.1 & 120 \\
\hline 9 & $\begin{array}{l}\text { Plasterboard } \\
\text { [type 03] }\end{array}$ & 0.0125 & 0.39 & & 1.0 & 1200 \\
\hline 10 & $\begin{array}{l}\text { photo-catalytic } \\
\text { cement panel }\end{array}$ & 0.0150 & 0.42 & & 1.0 & 1400 \\
\hline 11 & $\begin{array}{l}\text { External surface } \\
\text { resistance }\end{array}$ & & & 0.04 & & \\
\hline
\end{tabular}

The evaluation performed showed that the preassembled module allows obtaining very good results in terms of energy performance as table 3 and related graph summarize. The graph shows the thermal lag according to daily temperature trend for hour.

\section{Final remarks}

The evaluations performed showed that the defined preassembled modules based on a multilayer concept can be easily adapted to different climate and context conditions just varying the insulation typology and/or characteristics without any relevant change in the section arrangement and its thickness. This represents a key 
Table 3: Evaluation results.

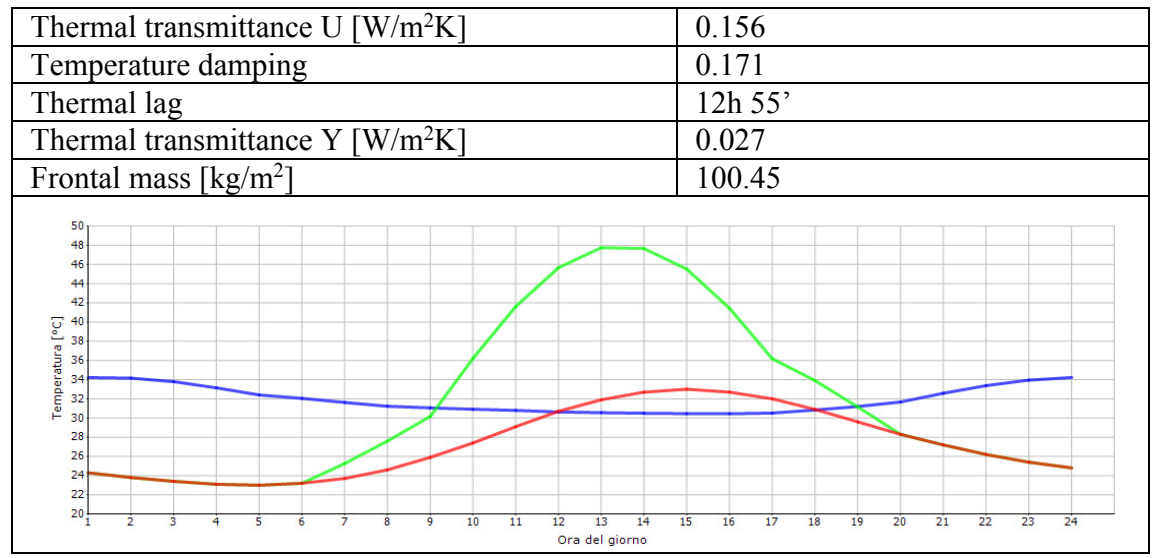
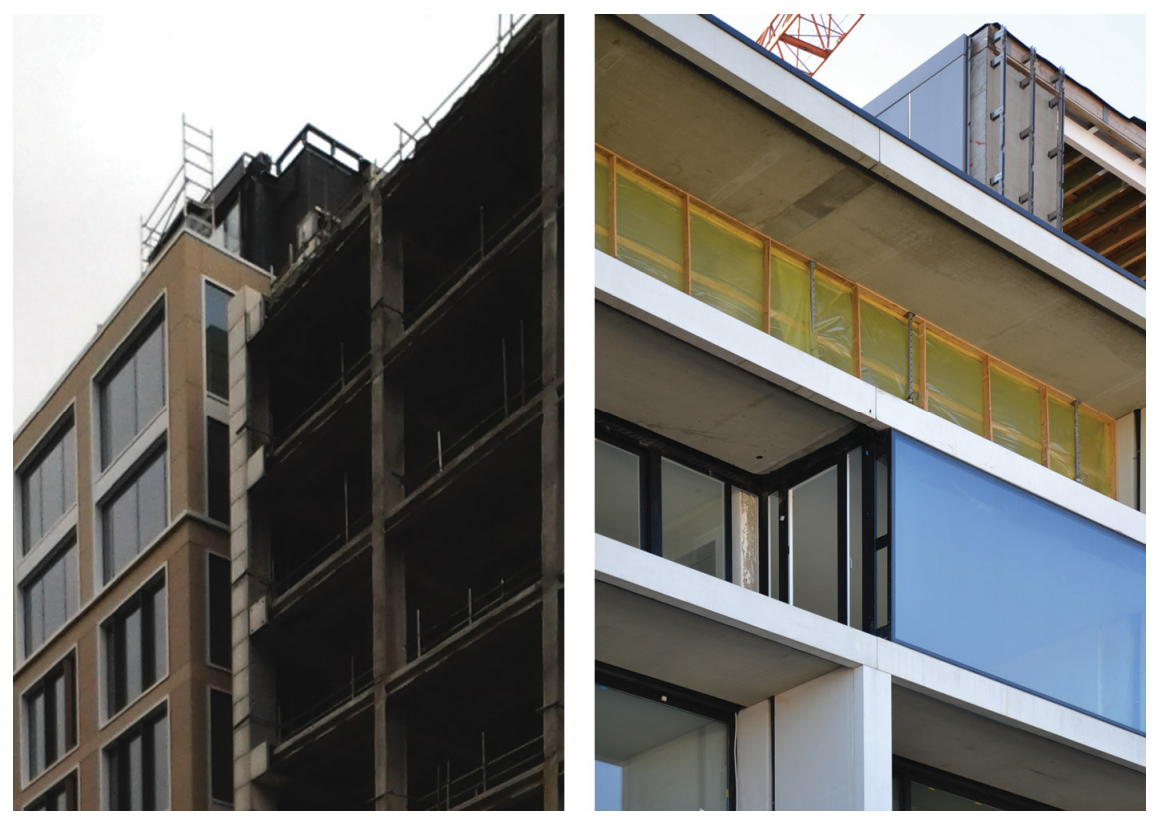

Figure 5: Examples of existing buildings under renovation.

factor in pursuing an effective pre-assembling procedure which aims to cover the widest field of application. The choice to have floor-to-floor modules as well the chance to adapt the panel size to the existing façade pace (or to submultiples of it) are addressed to overcome the potential geometrical constraints which represents one of the most frequent barrier when preassembled solutions are applied on existing buildings (see figure 5). While the advantages concerning the reduction 
of construction time and impacts on the building site are quite clear, the economic feasibility of the intervention still represents the most recurring barrier in this filed. The investment feasibility calculation is in general carried out by using the Discounted Cash Flow [DCF] method [14], where all the present and future inflows and outflows are discounted to obtain the Net Present Value [NPV], the Internal Rate of Return [IRR] or the discounted payback period [DPBP]. The NPV, IRR or payback time period can vary in relation to the effectiveness criteria the evaluation is based on [15]. The payback time of preassembled option developed for scenario 01 is around 9 years which is usually perceived as a suitable solution, as the expected average payback time is around 10 years.

Despite single interventions are technically possible, the renovation has to involve the whole façade in order to meet the economic feasibility, which is often a limit when the property is fragmented due to decisional barriers. However, the reduction of time and impacts, which allow operating without the tenants moving out of the apartments, encourages to overcome these kinds of obstacles.

\section{References}

[1] Dol, K. \& Haffner, M., (eds). Housing Statistics in the European Union, OTB Research Institute for the Built Environment, Delft University of Technology: Delft, 2010.

[2] Economidou, M., (eds). Europe's buildings under the microscope. A country-by-country review of the energy performance of buildings, Buildings Performance Institute Europe (BPIE): Brussels, 2011.

[3] Boeri, A. \& Longo, D., From the Redevelopment of High-density Suburban Areas to Sustainable Cities. ARCHITECTONICA, pp.118-130, 2012.

[4] Melgaard, E., Hadjimichael, G., Almeida, M. \& Verhoef L. G. W. (eds), Improving the quality of Existing building envelopes, IOS Press: Washington, 2007.

[5] Evans, R., Barriers to energy efficiency. A report for the Energy Efficiency Office, London, 1991.

[6] Hirst, E. \& Brown, M., Closing the efficiency gap: barriers to the efficient use of energy. Resources, Conservation and Recycling, 3(4), pp. 267-281, 1990.

[7] Tuominen, P., Klobuta, K., Tolmana, A., Adjeib, A. \& de Best-Waldhoberc, J., Energy savings potential in buildings and overcoming market barriers in member states of the European Union. Energy and Buildings, 51, pp. 48$55,2012$.

[8] Watts, A., Modern construction envelopes, Springer Wien Architecture, Wien, 2010.

[9] Tichelmann, K. \& Pfau, J., Dry construction: principles, details, examples, Birkhauser Architecture: Basel, 2008.

[10] Boeri, A., Gaspari, J., Longo, D., Methodology for improving and testing the quality of renovation actions: a case study application. Sustainable buildings construction products \& technologies, ed. Passer, A., Höfler, K. \& Maydl, P., Verlag der Technischen Universität Graz: Graz, 2013. 
[11] Peixoto de Freitas, V. \& Delgado J.M.P.Q., (eds). Hygrothermal Behavior, Building Pathology and Durability, Springer, Heidelberg, New York, Dordrecht, London, 2013.

[12] De Joanna, P., Francese, D. \& Passaro A., (eds). Sustainable mediterranean construction, Franco Angeli: Milano, 2012.

[13] Moss, K. J., Heat and mass transfer in building service design, Spon Press Routledge: New York, 2005 (first ed. 1998).

[14] Hendricks, L., Quality and economy - A performance-based approach to real estate and real estate portfolios, Government Buildings Agency, The Hague, The Netherlands, 1998.

[15] Boeri, A., Antonini, E., Gabrielli, L., Longo, D. \& Roversi, R., Social Housing: refurbishment strategies and economic valuation for high density buildings. Improving the quality of suburban building stock, ed. Di Giulio R., Unifepress: Ferrara, vol. 1: pp. 387-392, 2012. 